\title{
Myxofibrosarcoma of the sinus piriformis: case report and literature review
}

\author{
Zhu Qiubei ${ }^{1}$, Lin Cheng ${ }^{2}$ Xu Yaping ${ }^{1}$, Lin Shunzhang ${ }^{1}$ and Fan Jingping ${ }^{1 *}$
}

\begin{abstract}
Myxofibrosarcoma is a common sarcoma in the extremities of older people, but is rare in the head and neck region. Here, we report the case of a 42-year-old male patient in whom myxofibrosarcoma generated from the sinus piriformis. Histopathologically, the tumor was characterized by spindle cellular proliferation with moderate cellular density in fibromyxoid stroma. Immunohistochemically, the tumor cells showed positive reactivity for vimentin, Ki-67, smooth muscle actin, and CD34, but negative staining for S-100. Based on these results, the tumor was diagnosed as a low-grade myxofibrosarcoma. Resection of the tumor was performed via a transcervical approach. The patient's postoperative clinical course was uneventful and no local recurrence or distant metastasis has been found so far. The pathology, clinical characteristics, and treatment of myxofibrosarcoma are also reviewed.
\end{abstract}

Keywords: Myxofibrosarcoma, Sinus piriformis

\section{Background}

As one of the most common sarcomas, myxofibrosarcoma (MFS) is originally described as a myxoid variant of malignant fibrous histiocytoma (MFH), the unique characteristic of which can be ascribed as its frequent occurrence in the subcutaneous tissues of the extremities of older people. Myxofibrosarcoma rarely occurs in the head and neck regions [1], and only a few corresponding cases in these areas have been reported, with $3 \%$ to $10 \%$ involvement, including the larynx [2], esophagus [3], sphenoid sinus [4,5], mandible [6], maxillary sinus [7], parotid [8,9], orbit [10,11], and infratemporal space [12]. To our knowledge, only one case has so far been reported regarding MFS generated from the hypopharynx [13].

The objective of this work was to report an additional case of MFS arising in the sinus piriformis. The clinical, radiological, and histopathological characteristics of this tumor were also reviewed. Three years after operation, the postoperative clinical course was uneventful and no evidence of recurrence or metastasis and symptoms in the throat were observed in this patient.

\footnotetext{
* Correspondence: jingping_fan@hotmail.com

'Department of ear, nose and throat, Changzheng Hospital, No 415,

Fengyang Road, Shanghai, Huangpu District 200003, China

Full list of author information is available at the end of the article
}

\section{Case presentation}

A 42-year-old Chinese man had felt an unpleasant sensation in the throat since July 2005 . He visited a local otorhinolaryngology clinic and a tumor was found in the hypopharynx. The tumor was resected surgically under a laryngoscope in October 2005. However, the patient still complained of a mass coming from the deep throat sooner after the operation. When vomiting, he could feel the mass coming from his throat into his mouth, and when swallowing, the mass would go downward. A barium meal (baM) examination of the esophagus showed that the cervical segment, about $14 \mathrm{~cm}$ from the cutting tooth, was broadened to $50 \mathrm{~mm}$, and the broadened segment was $50 \mathrm{~mm}$ long (Figures 1a,b). An $\mathrm{X}$-ray of the chest showed that the trachea leaned to the right (Figure 1c). A computed tomography (CT) scan revealed an irregular-shaped mass in the esophagus, which seemed to originate in the hypopharynx. The mass was $90 \mathrm{~mm}$ long and $25 \mathrm{~mm}$ wide; the first $40 \mathrm{~mm}$ was thin and flat, and the last $50 \mathrm{~mm}$ was globular (Figures 2a,b). The patient felt that the mass had been growing slowly over the previous 2 years. Accordingly, he visited our hospital on November 10, 2008. On examination, we found that the surface of the mass was smooth, like normal mucosa. The laryngeal endoscopy and electronic gastroscopy showed that the pedicle of the mass arose from the medial wall of the left 

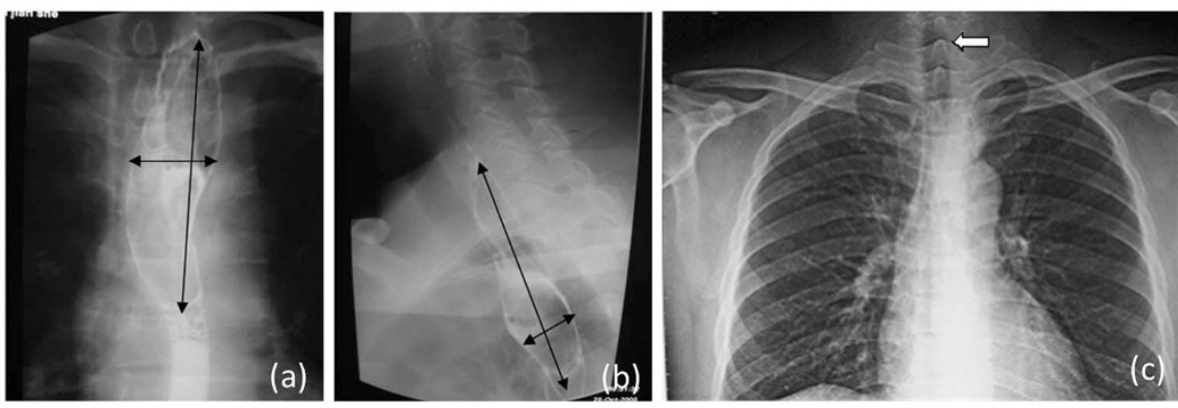

Figure 1 Barium meal (baM) examination of esophagus showing significant broadening in the cervical segment. (a) Front view (b) Side view. (c, arrow) X-ray of the chest showed that the trachea leaned to the right.

sinus piriformis at the level of the aryepiglottic fold (Figures 3a,b,c). The tumor shifted downward and upward when swallowing. There was no relationship between the mass and the esophageal mucosa. The pedicle of the mass was $50 \mathrm{~mm}$ long, and the mass itself $40 \mathrm{~mm}$ long, and this led to incomplete resection of the mass under the laryngoscope. Based on the histological and the pathological diagnosis of the previous surgery, we supposed that the mass was a recurrent or persistent MFS. We performed tumor resection and wound suture via a transcervical approach on November 28,2008 . The mass was well demarcated, $30 \mathrm{~mm} \times 20 \mathrm{~mm}$ in diameter and the cut surface was mucous yellow-gray and translucent (Figure 4).

Pathological findings showed typical features of lowgrade MFS. The tumor was characterized by spindle-cell proliferation with moderate cellular density in the fibromyxoid stroma (Figure 5). Immunohistochemically, the tumor cells were positive for vimentin, Ki-67, smooth muscle actin (SMA), and CD34, but negative for S-100 (see Figure 6). Thus, the tumor was ultimately diagnosed with low-grade myxofibrosarcoma (myxoid MFH). The surgical margin was sufficient. The postoperative clinical course was uneventful and the patient had no symptoms in the throat after the operation.

\section{Discussion}

Malignant fibrous histiocytoma is the most common malignant soft-tissue tumor in adults [14]. Histopathologically, MFH can be divided into five subtypes: storiform-pleomorphic, myxoid, giant cell, inflammatory, and angiomatoid [15-17]. The term MFS is proposed as a synonym for myxoid MFH and covers a spectrum of malignant fibroblastic lesions, which have cellular distribution, pleomorphism of the nucleus, and mitotic activity that varies from a less cellular lesion with minimal cytologic atypia to a greater cellular lesion with pronounced atypical features [18,19]. Myxofibrosarcoma usually grows slowly and painlessly in the extremities of older people, with a slight male predominance [19]. Superficially located MFS typically consist of multiple variably gelatinous or firmer nodules, with a myxoid cut surface, whereas deep-seated neoplasms often form a single mass with an infiltrative margin. However, MFS is uncommon in the head and neck region. Only 18 cases have been described in the head and neck so far (Table 1), our case being the second in the hypopharynx.

Histologically, MFS may exhibit various proportions of myxoid matrix with varied cellularity. Thus, it is suggested that MFS be subdivided into four [28] or three [29] grades according to the degree of cellularity,
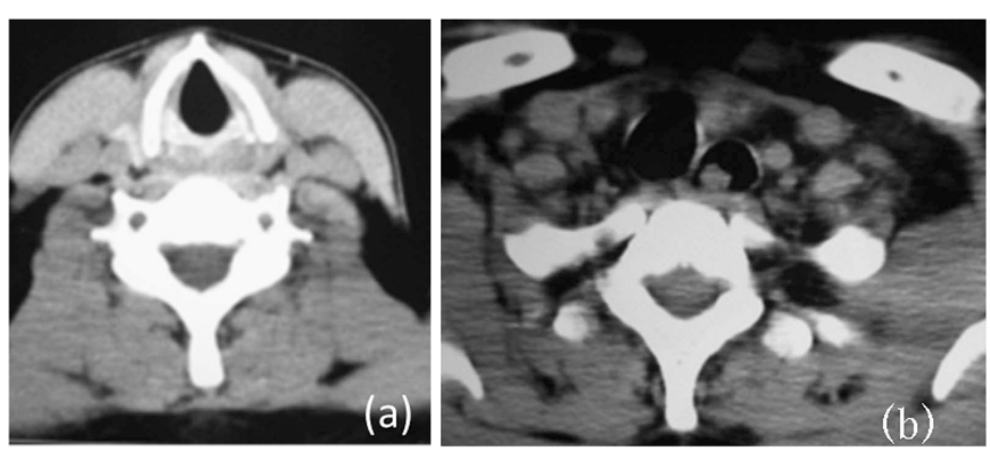

Figure $\mathbf{2}$ CT showing the mass in the esophagus. (a) The larynx was normal. (b) The esophagus was dilated and the left bronchus was compressed (arrow shows the mass). 

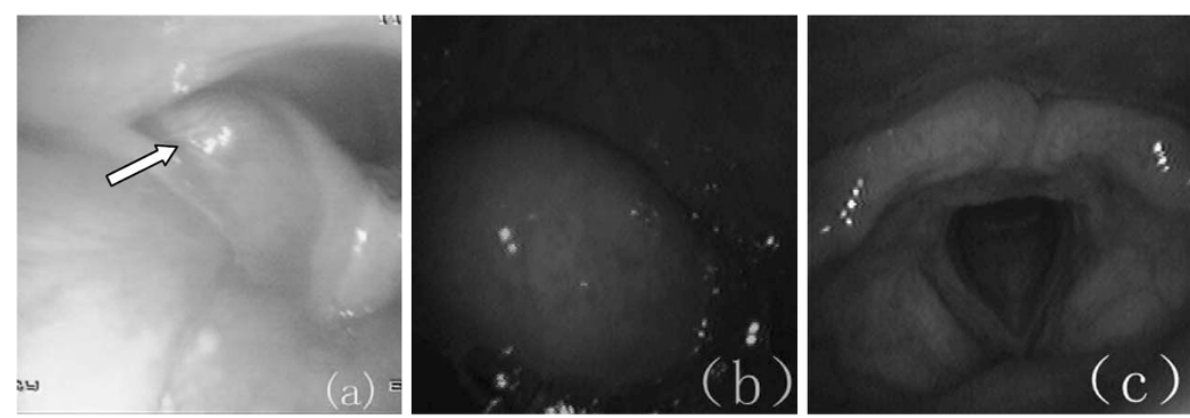

Figure 3 Local finding of the hypopharynx. The tumor was located at the hypopharyngeal left sidewall. The surface was smooth and it was the same normal color as the surrounding mucosa. (a) Arrow indicates the base of the pedicle, coming from the left piriform sinus. (b) Mass in the pharynx when vomiting. (c) The larynx was normal.

pleomorphism of the nucleus, and mitotic activity. Lowgrade MFS shows a hypocellular to moderately cellular architecture with a prominent myxoid matrix. Tumor cells are fusiform, round, or stellate, with ill-defined, slightly eosinophilic cytoplasm and atypical, enlarged, hyperchromatic nuclei (Figure 5). Mitoses can only seldom be seen $[1,26]$. Most of the tumors have stretched and curved capillaries, and the tumor cells tend to be located along the vessel periphery. Another finding worth mentioning is the presence of prominent elongated, curvilinear, thin-walled blood vessels with a perivascular condensation of tumor cells or inflammatory cells (mainly lymphocytes and plasma cells). Although magnetic resonance imaging and CT scans evidently make a great contribution to the visualization of malignant features, such as local tissue invasion, histopathological examination is recognized as the gold standard, for its capability to provide a definitive diagnosis [30]. Immunohistochemically, low-grade MFS is generally positive for CD-34, vimentin [1], and sometimes for SMA and Ki-67 [31], while negative for S-100 protein. The histopathological findings of the present case were further consistent with a diagnosis of low-grade

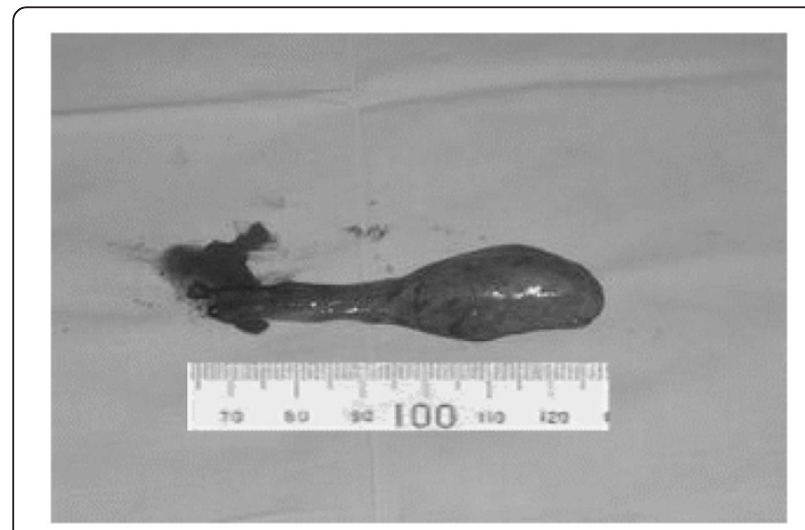

Figure 4 Overall view of the tumor. myxofibrosarcoma and immunoreactivity to vimentin and CD34, probably reflecting the tumor's primitive fibroblastic nature.

Complete tumor resection with adequate resection margin remains the mainstay for treatment of MFS. The radiotherapy is applied only for recurrent, unresectable lesions or tumors with positive resection margins, to suppress local recurrence and the risk of histologic progression, especially for low-grade MFS. The value of chemotherapy in MFS is still an issue for open debate [5]. Low-grade MFS is considered to have low malignancy, and rarely shows distant metastasis, implying a good short-term prognosis. The overall 5 -year survival rate is $60 \%$ to $70 \%$ [23]. However, the local recurrence rate of the low-grade type is as high (50\% to $60 \%)$ as that of the high-grade type. It has continuity from low- to high-grade subdivision, showing low-grade areas in high-grade lesions, and a histologic progression of lowto high-grade tumors in recurrences, hence acquiring metastatic potential $[15,29]$. Therefore, these patients

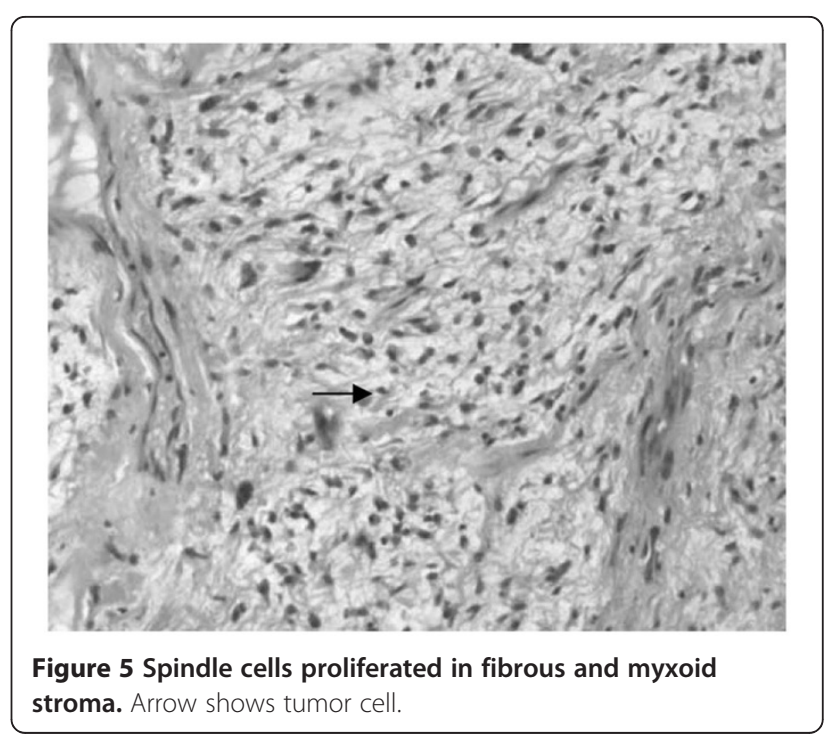




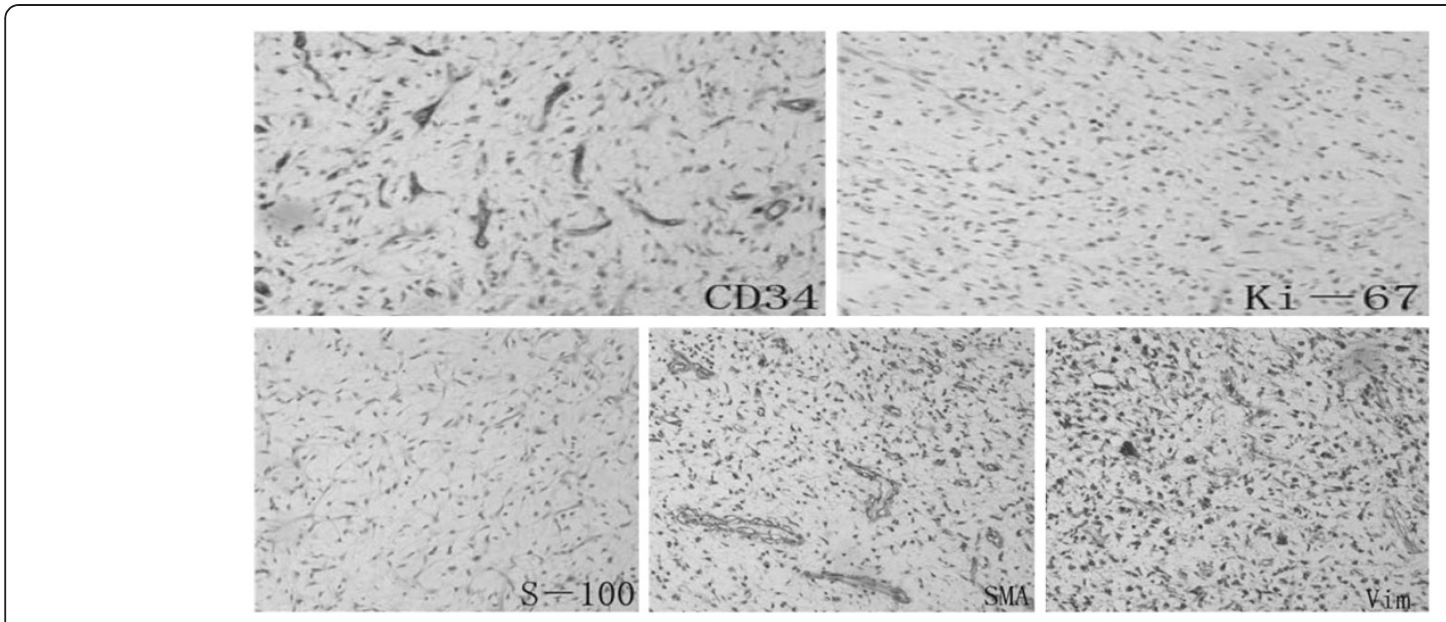

Figure 6 Immunohistochemical reactivity of the tumor cells. Positive for vimentin, Ki-67, smooth muscle actin, CD34, but negative for S-100 Vim, vimentin; SMA, smooth muscle actin.

should be placed under careful and long-term follow-up. Complete resection of the tumor was accomplished in our case and this patient showed no recurrence and metastasis three years after the operation.

\section{Conclusions}

In summary, we report a rare case of MFS that generated from the sinus piriformis. Histopathological examination is the gold standard for offering a definitive diagnosis, and the prognosis is accurate after complete resection and careful surveillance. Local recurrence may occur generally with progression of the tumor stage and risk of later metastasis. In this case, the hypothesis that the tumor is recurrent may be reasonable because of the insufficient resection in the previous operation. This emphasizes the recurrent character of MFS and the importance of sufficient resection.

\section{Consent}

Written informed consent was obtained from the patient for publication of this case report and any accompanying images. A copy of the written consent is available for review by the editor-in-chief of this journal.

Table 1 Cases of myxofibrosarcoma in the head and neck region

\begin{tabular}{|c|c|c|c|c|c|c|}
\hline Author & Year & Sex & Age & Tumor extent & Treatment & Results \\
\hline Blitzer et al. [20] & 1981 & Male & 66 & Sphenoid sinus & Radiotherapy & Died after 3 months \\
\hline Pomerantz et al. [21] & 1982 & Male & 58 & Maxillary sinus & Surgery & Unknown \\
\hline Barnes and Kanbour [22] & 1988 & Female & 67 & Sphenoid sinus-cavernous sinus & Surgery, adjuvant radiotherapy & Alive after 8 months \\
\hline Imai et al. [11] & 2000 & Female & 52 & Orbit & Surgery & Unknown \\
\hline Lam et al. [23] & 2002 & Male & 55 & Left sphenoid sinus & Surgery & Alive after 8 months \\
\hline Iguchi et al. [24] & 2002 & Male & Unknown & Maxillary & Unknown & Unknown \\
\hline Song and Miller [3] & 2002 & Male & 40 & Esophagus & Surgery & Unknown \\
\hline Nishimura et al. [13] & 2006 & Male & 69 & Hypopharynx & Surgery & Alive after 16 months \\
\hline Udaka et al. [1] & 2006 & Male & 55 & Neck & Surgery & Alive after 27 months \\
\hline Enoz and Yusufhan [25] & 2007 & Female & 36 & Maxillary sinus & Surgery & Alive after 2 years \\
\hline Gugatschka et al. [26] & 2010 & Male & 79 & Vocal folds & Surgery & Unknown \\
\hline Xu et al. [8] & 2010 & Female & 37 & Parotid & Surgery, radiotherapy & Alive after 8 months \\
\hline Zhang et al. [10] & 2010 & Female & 27 & Orbit & Surgery, radiation & Alive after 6 months \\
\hline Zouloumis et al. [6] & 2010 & Male & 23 & Mandible & Surgery, radiotherapy & Alive 39 months \\
\hline Norval et al. [7] & 2011 & Male & 69 & Maxillary sinus & Radiotherapy, chemotherapy & Died after 1 year \\
\hline Srinivasan et al. [9] & 2011 & Female & 78 & Parotid & Surgery, radiotherapy & Died after 24 months \\
\hline Krishnamurthy et al. [12] & 2011 & Female & 42 & Infratemporal space & Surgery, radiotherapy & Alive after 26 months \\
\hline Nakahara et al. [27] & 2012 & Male & 52 & Maxilla & Surgery, radiotherapy & Alive after 20 months \\
\hline
\end{tabular}




\section{Abbreviations}

CT: computed tomography; MFH: malignant fibrous histiocytoma; MFS: myxofibrosarcoma; SMA: smooth muscle actin.

\section{Competing interests}

The authors declare that they have no competing interests.

\section{Authors' contributions}

ZQ and LC participated in the design of this study. XY carried out the study, together with LS, who collected important background information and drafted the manuscript. FJ conceived this study, participated in the design, and helped to draft the manuscript. All authors read and approved the final manuscript.

\section{Authors' information}

Zhu Qiubei and Lin Cheng should be regarded as co-first authors.

\section{Author details}

${ }^{1}$ Department of ear, nose and throat, Changzheng Hospital, No 415, Fengyang Road, Shanghai, Huangpu District 200003, China. ${ }^{2}$ Department of ear, nose and throat, The 452nd Hospital of PLA, Gongnongyuan Street, Chengdu, Sichuan Province, China.

Received: 3 July 2012 Accepted: 21 September 2012 Published: 15 November 2012

\section{References}

1. Udaka T, Yamamoto H, Shiomori T, Fujimura T, Suzuki H: Myxofibrosarcoma of the neck. J Laryngol Otol 2006, 120:872-874.

2. Prasad I, Sharan R: Myxofibrosarcoma of larynx. Indian J Otolaryngol Head Neck Surg 1981, 33(2):71-71.

3. Song HK, Miller Jl: Primary myxofibrosarcoma of the esophagus. J Thorac Cardiovasc Surg 2002, 124(1):196-197.

4. Enomoto K, Inohara H, Hamada K, Tamura M, Tomita Y, Kubo T, Hatazawa J: FDG PET imaging of myxofibrosarcoma on the sphenoid sinus. Clin NuCl Med 2008, 33(6):421-422

5. Lam PK, Trendell-Smith N, Li JH, Fan YW, Yuen AP: Myxofibrosarcoma of the sphenoid sinus. J Laryngol Otol 2002, 116(6):464-466.

6. Zouloumis L, Ntomouchtsis A, Lazaridis N: Giant myxofibrosarcoma of the mandible. Balkan Journal of Stomatology 2010, 14(1):41-44.

7. Norval EJG, Raubenheimer EJ: Myxofibrosarcoma arising in the maxillary sinus: a case report with a review of the ultrastructural findings and differential diagnoses. J Maxillofac Oral Surg 2011, 10:334-339.

8. Li X, Chen X, Shi ZH, Chen Y, Ye J, Qiao L, Qiu JH: Primary myxofibrosarcoma of the parotid: case report. BMC Cancer 2010, 10:246.

9. Srinivasan B, Ethunandan M, Hussain K, llankovan V: Epitheloid myxofibrosarcoma of the parotid gland. Case Report Pathol 2011, 2011:641621.

10. Zhang Q, Wojno TH, Yaffe B, Grossniklaus HE: Myxofibrosarcoma of the orbit. Ophthal Plast Reconstr Surg 2010, 26(2):129.

11. Imai $Y$, Sugawara $Y$, Okazaki M, Harii K: Low grade myxofibrosarcoma in the orbit: a case report. Japanese J Plastic Reconstructive Surg 2000, 43(4):401-409.

12. Krishnamurthy A, Vaidhyanathan A, Majhi U: Myxofibrosarcoma of the infratemporal space. $J$ Cancer Res Ther 2011, 7(2):185.

13. Nishimura G, Sano D, Hanashi M, Yamanaka S, Tanigaki Y, Taguchi T, Horiuchi C, Matsuda H, Mikami Y, Tsukuda M: Myxofibrosarcoma of the hypopharynx. Auris Nasus Larynx 2006, 33(1):93-96.

14. Al-Agha OM, Igbokwe AA: Malignant fibrous histiocytoma: between the past and the present. Arch Pathol Lab Med 2008, 132(6):1030-1035.

15. Enjoji M, Hashimoto $\mathrm{H}$, Tsuneyoshi M, Iwasaki $\mathrm{H}$ : Malignant fibrous histiocytoma. Pathol Int 1980, 30(5):727-741.

16. Park SW, Kim HJ, Lee J, Ko YH: Malignant fibrous histiocytoma of the head and neck: CT and MR imaging findings. Am J Neuroradiol 2009, 30(1):71-76.

17. Matushansky I, Charytonowicz E, Mills J, Siddiqi S, Hricik T, Cordon-Cardo C: MFH classification: differentiating undifferentiated pleomorphic sarcoma in the 21st century. Expert Rev Anticancer Ther 2009, 9(8):1135.

18. Angervall L, Kindblom LG, Merck C: Myxofibrosarcoma. A study of 30 cases. Acta Pathol Microbiol Scand A 1977, 85(2):127-140.
19. Fletcher CDM, Unni KK, Mertens F (Eds): Pathology and Genetics of Tumours of Soft Tissue and Bone. Lyon: IARC Press; 2002.

20. Blitzer A, Lawson W, Zak FG, Biller HF, Som ML: Clinical--pathological determinants in prognosis of fibrous histiocytomas of head and neck. Laryngoscope 1981, 91(12):2053-2070.

21. Pomerantz J, Sanfacon D, Dougherty T, Hanson S: Myxofibrosarcoma of the maxillary sinus. Del Med J 1982, 54(3):147-152.

22. Barnes $L$, Kanbour A: Malignant fibrous histiocytoma of the head and neck: a report of 12 cases. Arch Otolaryngol Head Neck Surg 1988, 114(10):1149-1156.

23. Nishio J, Iwasaki H, Nabeshima K, Naito M: Cytogenetics and molecular genetics of myxoid soft-tissue sarcomas. Genet Res Int 2011, 2011:497148.

24. Iguchi $Y$, Takahashi H, Yao K, Nakayama M, Nagai H, Okamoto M: Malignant fibrous histiocytoma of the nasal cavity and paranasal sinuses: review of the last 30 years. Acta Otolaryngol Suppl 2002, 122(4):75-78.

25. Enoz M, Suoglu Y: Myxofibrosarcoma of the maxillary sinus. Internet J Head Neck Surg 2007, 1(1):1-4.

26. Gugatschka M, Beham A, Stammberger H, Schmid C, Friedrich G: First case of a myxofibrosarcoma of the vocal folds: case report and review of the literature. J Voice 2010, 24(3):374-376.

27. Nakahara S, Uemura H, Kurita T, Suzuki M, Fujii T, Tomita Y, Yoshino K. A case of myxofibrosarcoma of the maxilla with difficulty in preoperative diagnosis. Int J Clinical Oncol 2012, 17:390-394.

28. Merck C, Angervall L, Kindblom LG, Odén A: Myxofibrosarcoma. A malignant soft tissue tumor of fibroblastic-histiocytic origin. A clinicopathologic and prognostic study of 110 cases using multivariate analysis. Acta Pathol Microbiol Immunol Scand Suppl 1983, 282:1-40.

29. Mentzel T, Calonje E, Wadden C, Camplejohn RS, Beham A, Smith MA Fletcher CDM: Myxofibrosarcoma: clinicopathologic analysis of 75 cases with emphasis on the low-grade variant. Am J Surg Pathol 1996, 20(4):391.

30. Kaya M, Wada T, Nagoya S, Sasaki M, Matsumura T, Yamaguchi T, Hasegawa T, Yamashita T: MRI and histological evaluation of the infiltrative growth pattern of myxofibrosarcoma. Skeletal Radiol 2008, 37(12):1085-1090.

31. Ayache S, Chatelain D, Tramier B, Strunski V: Oropharyngeal and hypopharyngeal myxoma: case report and literature review. J Laryngol Otol 2007, 121(5):1-4.

doi:10.1186/1477-7819-10-245

Cite this article as: Qiubei et al:: Myxofibrosarcoma of the sinus piriformis: case report and literature review. World Journal of Surgical Oncology 2012 10:245.

\section{Submit your next manuscript to BioMed Central and take full advantage of:}

- Convenient online submission

- Thorough peer review

- No space constraints or color figure charges

- Immediate publication on acceptance

- Inclusion in PubMed, CAS, Scopus and Google Scholar

- Research which is freely available for redistribution 